\title{
Para além da filiação religiosa: religião, religiosidade e o panorama religioso em Ribeirão das Neves - MG, Brasil
}

\author{
Beyond the religious affiliation: religion, religiosity and the religious \\ panorama in Ribeirão das Neves, Minas Gerais, Brazil.
}

\author{
Paula Miranda-Ribeiro* \\ Adriana Miranda-Ribeiro**
}

\begin{abstract}
Resumo
Conhecer o panorama religioso no nível nacional e ao longo do tempo pode ser considerado um privilégio do Brasil, cujos censos demográficos coletam informações a esse respeito pelo menos desde 1940. No entanto, a literatura sugere que a filiação religiosa não é suficiente para entender o papel da religião na vida dos indivíduos. Sendo assim, o objetivo deste artigo é mostrar, através do exemplo de Ribeirão das Neves, MG-Brasil, a importância da religiosidade no panorama religioso. O estudo combina dados do Censo Demográfico de 2000 com informações sobre estudantes do Ensino Médio da rede pública estadual coletados pela Pesquisa Jovem, levando em consideração não apenas a filiação religiosa, mas, também, a frequência às cerimônias e a frequência com que se reza/ora fora das cerimônias religiosas. Os resultados do Censo 2000 sugerem que o município de Ribeirão das Neves é distinto de Minas Gerais e do Brasil no que tange à filiação religiosa. A inclusão da frequência às cerimônias e de medida de religiosidade no âmbito doméstico desvenda outros aspectos relativos à religião, sugerindo que ir além da filiação religiosa pode ajudar a compreender melhor a complexidade do panorama religioso.
\end{abstract}

Palavras-chave: Religião. Religiosidade. Ensino Médio. Juventude. Ribeirão das Neves, Brasil

\begin{abstract}
Knowledge of the religious landscape over time and at the national level could be considered a privilege of Brazil. Brazilian demographic censuses have collected information related to religion since 1940. However, the literature suggests that religious affiliation is not sufficient for understanding the role of religion in the lives of individuals. Thus, the objective of this article is to show the importance of religiosity in the religious landscape, using the example of Ribeirão das Neves, Minas Gerais, Brazil. The study combines data from the Demographic Census of 2000 with information about high school students in the state-run, public school system collected by the Pesquisa Jovem (Youth Survey). The study takes into consideration not only religious affiliation, but also attendance at worship services and the frequency with which individuals pray outside of worship services. The results of the 2000 Census suggest that the municipality of Ribeirão das Neves is distinct from Minas Gerais and Brazil in relation to religious affiliation. The inclusion of attendance at worship ceremonies and a measurement of religiosity in the home reveal other aspects related to religion, suggesting that going beyond religious affiliation may help to better understand the complexity of the religious panorama.
\end{abstract}

Key words: Religion. Religiosity. High School. Youth. Ribeirão das Neves, Brazil

\footnotetext{
Artigo recebido em 31 de outubro de 2011 e aprovado em 24 de novembro de 2011.

* Doutora em Sociologia, Professora Associada do Departamento de Demografia e do CEDEPLAR, Universidade Federal de Minas Gerais, Brasil. E-mail: paula@cedeplar.ufmg.br

${ }^{* *}$ Doutora em Demografia, Analista de Pesquisa e Ensino do Centro de Estatística e Informações da Fundação João Pinheiro, Brasil. E-mail: ricaadri@gmail.com
} 


\section{Introdução}

$\mathrm{O}$ século $\mathrm{XX}$ foi testemunha de uma contundente mudança no panorama religioso brasileiro. Dados dos censos demográficos revelam uma forte redução da proporção daqueles que se autodeclaram católicos e, ao mesmo tempo, um aumento expressivo da proporção de evangélicos e sem religião. Entre 1940 e 2000, a proporção de católicos passou de $95 \%$ para $73,6 \%$ e os evangélicos pularam de $2,6 \%$ para $15,4 \%$, enquanto os sem religião saltaram de meros $0,2 \%$ para $7,4 \%$ da população brasileira (IBGE, 2007). A década de 1990 foi palco de grandes mudanças, uma vez que a proporção de católicos caiu 10 pontos percentuais, o grupo declarado evangélico cresceu $70 \%$ e a proporção dos sem religião praticamente quintuplicou entre 1991 e 2000 (IBGE, 2004).

Conhecer o panorama religioso no nível nacional e ao longo do tempo pode ser considerado um privilégio do Brasil, cujos censos demográficos coletam informações sobre a filiação religiosa pelo menos desde 1940. No entanto, a literatura sugere que esta variável não é suficiente para entender o papel da religião na vida dos indivíduos. Sendo assim, o objetivo deste artigo é ir além da filiação religiosa e, a partir do exemplo de Ribeirão das Neves-MG, sugerir que a inclusão de variáveis ligadas à religiosidade contribuem para uma melhor compreensão do panorama religioso. Para tal, o estudo combina dados do Censo Demográfico de 2000 com informações sobre estudantes do Ensino Médio da rede pública estadual coletados pela Pesquisa Jovem, levando em consideração não apenas a filiação religiosa, mas também a frequência às cerimônias e a frequência com que reza/ora/faz preces fora das cerimônias religiosas.

O artigo está organizado em cinco seções. Após esta introdução, é apresentada uma breve revisão sobre a importância da religiosidade nos estudos demográficos. A seção 2 descreve os dados utilizados, enquanto a seção 3 apresenta os resultados, seguida dos comentários finais.

Os resultados do Censo 2000 indicam que o município de Ribeirão das Neves é distinto de Minas Gerais e do Brasil no que tange ao cenário religioso, quando medido pela filiação religiosa. A inclusão da frequência às cerimônias e frequência com que reza/ora, por sua vez, desvenda outros aspectos relativos à religião no município, os quais podem contribuir para a compreensão da complexidade do panorama religioso brasileiro. 


\section{Para além da filiação religiosa}

A literatura internacional sugere que o papel da religião é mais bem compreendido se, além da filiação religiosa, for considerada também a participação religiosa ou a religiosidade. Argumenta-se que, se a religião tem impacto sobre o comportamento social, econômico e demográfico dos indivíduos, então, esse efeito pode ser ainda maior entre aqueles que são mais frequentes às cerimônias ou seguem mais de perto os ensinamentos da sua religião (ELLISON; HUMMER, 2010; THORNTON; CAMBURN, 1989; LEHRER, 2004).

Para utilizar medidas de participação religiosa e religiosidade, os autores costumam esbarrar na disponibilidade de dados (LEHRER, 2004). Nos Estados Unidos, apesar do Censo Demográfico não perguntar sobre religião desde 1946, há uma série de pesquisas disponíveis para aqueles que queiram levar esta dimensão em consideração, a começar pelo General Social Survey (GSS), que começou a coletar informações sobre religião em 1973 (SHERKAT, 2010). Temas de interesse dos demógrafos, tais como mortalidade, fecundidade, nupcialidade e migração, vêm sendo amplamente investigados em suas relações com religião e religiosidade (ELLISON et al., 2000; HUMMER et al., 2004; ROGERS; KRUEGER; HUMMER, 2010; LEHRER, 1993; PEARCE, 2010; SMITH; SIKKINK; BAILEY, 1998; entre muitos outros). No caso brasileiro, além dos censos demográficos, a pergunta sobre filiação religiosa foi incluída recentemente na Pesquisa de Orçamento Familiar (POF) de 2008/2009. Fora da produção do IBGE, há bases de dados públicas cujas perguntas sobre religião vão além da filiação religiosa e, ao mesmo tempo, atendem aos interesses dos demógrafos. Aqueles que estudam temas ligados à saúde sexual e reprodutiva vêm utilizando a Pesquisa Nacional sobre Demografia e Saúde (PNDS) de 2006, que tem informações sobre religião em que a entrevistada foi criada, religião atual e frequência às cerimônias. Com base nestes dados, há estudos sobre a associação entre religião, religiosidade e iniciação sexual (VERONA; REGNERUS, 2009; 2011; VERONA; DIAS JÚNIOR, 2010; 2011a), fecundidade (OGLAND et al., 2010; VERONA; DIAS JÚNIOR, 2011b), nupcialidade (MIRANDA-RIBEIRO; LONGO; MARTELETO, 2010) e mortalidade infantil (VERONA et al., 2010). Uma revisão bibliográfica sistemática sobre religião, religiosidade e iniciação sexual aponta para outras medidas de religiosidade que 
não apenas a frequência religiosa (COUTINHO; MACHADO; MIRANDA-RIBEIRO, 2011). Foram listadas variáveis que dizem respeito à importância da religião na vida do respondente, frequência com que o respondente reza ou ora, participação em grupos de jovens, leitura diária da Bíblia, pregação do Evangelho, distribuição de material religioso, importância que o indivíduo dá ao que Deus acha dele(a), frequência religiosa e religiosidade dos pais, além de escalas de religiosidade. No entanto, segundo as autoras, estas últimas podem não ser a melhor medida de religiosidade, uma vez que elas captam a religiosidade de uma pessoa em relação ao seu contexto familiar e social - por exemplo, um indivíduo cuja família é muito religiosa pode se considerar pouco religioso se frequenta a Igreja apenas uma vez por semana, ao passo que outro, vindo de família que não costuma frequentar as cerimônias, pode se considerar muito religioso se comparece às cerimônias uma vez por semana. Coutinho, Machado e Miranda-Ribeiro (2011) sugerem, então, que a religiosidade seja medida no âmbito privado - por exemplo, orar ou ler a bíblia fora das cerimônias religiosas.

Em suma, a literatura indica que, além da filiação religiosa, a religiosidade tem um papel importante no entendimento dos fenômenos em estudo. É razoável assumir, portanto, que medidas de religiosidade ajudem na compreensão do panorama religioso de Ribeirão das Neves. Antes de apresentar evidências neste sentido, a próxima seção discorre sobre os dados utilizados no trabalho.

\section{Dados}

Foram utilizados dados do Censo Demográfico de 2000 e da Pesquisa Jovem, realizada pelo Cedeplar ${ }^{1}$ em Ribeirão das Neves, Ibirité, Governador Valadares e alguns municípios vizinhos entre 2007 e 2010 . A pesquisa longitudinal acompanhou estudantes de escolas da rede estadual mineira entre o $1^{\circ}$ e o $3^{\circ}$ ano do Ensino Médio, através de questionários autoaplicados nas escolas. Nesses três municípios, foi feita uma amostragem aleatória das escolas de Ensino Médio, ao passo que, nos municípios vizinhos, a amostragem levou em consideração a distância das escolas com relação às escolas nos

${ }^{1}$ Centro de Desenvolvimento e Planejamento Regional, Faculdade de Ciências Econômicas (Face), Universidade Federal de Minas Gerais. 
municípios de interesse, de forma que aquelas mais próximas das escolas dos municípios de interesse tivessem maior chance de entrar na amostra.

No caso de Ribeirão das Neves, foram entrevistadas duas coortes, uma composta pelos estudantes que estavam no $1^{\circ}$ ano do Ensino Médio em 2007 e outra formada por aqueles que estavam no $1^{\circ}$ ano em 2008. Para fins deste trabalho, foram usados apenas os dados da primeira coorte (2007), coletados em 2009, quando boa parte dos alunos estava no $3^{\circ}$ ano do Ensino Médio $(\mathrm{n}=739)$.

Incluído no questionário da amostra, o quesito sobre religião do Censo Demográfico 2000 perguntava: “Qual a sua religião ou culto?’. A resposta, aberta, permitia se declarar sem religião. A multiplicidade de respostas, vantajosa por usar categorias nativas e, portanto, ficar mais próxima da realidade, dificulta qualquer análise desagregada. Assim, neste trabalho, as religiões foram agrupadas em categorias analíticas de acordo com as definições das tabelas publicadas pelo IBGE e semelhantes às consideradas no questionário da Pesquisa Jovem. Foram estabelecidas sete categorias: católica, evangélica de missão, evangélica de origem pentecostal, outras evangélicas, outras religiosidades, sem religião e sem declaração.

Diferente do Censo, o questionário da Pesquisa Jovem traz várias perguntas sobre religião. A pergunta análoga à do censo é "Qual é a sua religião atualmente?" e as respostas, pré-codificadas, incluem as categorias Adventista, Assembleia de Deus, Batista, Candomblé, Católica, Deus é Amor, Espírita, Evangelho Quadrangular, Igreja Universal do Reino de Deus, Metodista, Presbiteriana, Testemunha de Jeová, Umbanda, sem religião e outra, sendo que esta última dá a possibilidade do(a) respondente informar uma religião diferente das treze possibilidades listadas. Além da filiação religiosa, o questionário de 2008 da Pesquisa Jovem tem outras oito perguntas relacionadas à religião. São elas: se sempre frequentou a religião atual; religião em que foi criado(a); religião da mãe; frequência com que vai às cerimônias da religião atual; frequência com que reza/ora/faz preces fora das cerimônias; frequência com que lê a bíblia fora das cerimônias; escala (entre 1 e 10) de religiosidade; e escala (entre 1 e 10) com que segue os ensinamentos da religião atual. Este artigo utiliza 3 das 9 variáveis sobre religião: filiação religiosa, frequência às cerimônias e se reza/ora fora das cerimônias. 
As tabelas 1 e 2 apresentam a distribuição dos estudantes da primeira coorte de Ribeirão das Neves em 2009, segundo sexo, idade e série cursada. Os homens são, em média, ligeiramente mais velhos que as mulheres e apresentam maior defasagem idadesérie.

Tabela 1

Distribuição dos estudantes segundo sexo e idade 1a coorte de Ribeirão das Neves, 2009

\begin{tabular}{lrrr}
\hline \hline Idade & Mulheres & Homens & Total \\
\hline 16 & 2,3 & 1,0 & 1,8 \\
17 & 51,0 & 42,7 & 47,6 \\
18 & 31,1 & 36,8 & 33,4 \\
19 & 8,5 & 11,6 & 9,7 \\
$20-24$ & 5,7 & 7,6 & 6,5 \\
$25-29$ & 0,5 & 0,0 & 0,3 \\
$30-34$ & 0,5 & 0,3 & 0,4 \\
$35-39$ & 0,5 & 0,0 & 0,3 \\
\hline $\mathrm{N}$ & 437 & 302 & 739 \\
\hline \hline
\end{tabular}

Fonte: Pesquisa Jovem, Ribeirão das Neves, 2009

Tabela 2

Distribuição dos estudantes segundo sexo e série cursada 1 a coorte de Ribeirão das Neves, 2009

\begin{tabular}{lrrr}
\hline \hline & Mulheres & Homens & Total \\
\hline $1^{\circ}$ ano EM & 0,9 & 1,0 & 0,9 \\
$2^{\circ}$ ano EM & 11,2 & 21,2 & 15,3 \\
$3^{\circ}$ ano EM & 87,4 & 77,5 & 83,4 \\
EJA & 0,2 & 0,3 & 0,3 \\
Não respondeu & 0,2 & 0,0 & 0,1 \\
\hline $\mathrm{N}$ & 437 & 302 & 739 \\
\hline \hline
\end{tabular}

Fonte: Pesquisa Jovem, Ribeirão das Neves, 2009 
A seguir, a seção 3 traz os resultados e está dividida em duas partes. A primeira, baseada nos dados dos censos demográficos, está restrita à filiação religiosa. Já a segunda utiliza os dados da Pesquisa Jovem e, portanto, incorpora aspectos ligados à religiosidade.

\section{Ribeirão das Neves no contexto religioso de Minas Gerais e do Brasil}

Ribeirão das Neves é um dos trinta e quatro municípios da Região Metropolitana de Belo Horizonte (RMBH). Com 296.376 habitantes em 2010, segundo dados do Censo Demográfico, Ribeirão das Neves tinha a segunda menor renda per capita da RMBH em 2008 - R\$ 4.409,33². Por abrigar penitenciárias e depender do núcleo da RMBH para as atividades econômicas, o município, estigmatizado, é conhecido como cidade-presídio e cidade-dormitório (SOUSA, 2008).

\section{a. 0 retrato do Censo 2000}

A Tabela 3 sugere que Minas Gerais é um estado muito religioso, uma vez que apenas 4,6\% se declaram sem religião, vis-à-vis 7,4\% no país como um todo. Além disso, o estado é mais católico que a média nacional - 78,7\% dos habitantes de Minas Gerais se declaram católicos, comparados a 73,6\% no Brasil. O município de Ribeirão das Neves, por sua vez, é menos católico que a média do Estado e do País - apenas 62,9\% da população do município se declara católica - e tem, ainda, uma elevada proporção de habitantes que se declaram sem religião (9,3\%). Se comparado com Minas e o Brasil, Ribeirão das Neves tem uma sobrerrepresentação de evangélicos, que somavam $25 \%$ da sua população em 2000, contra 15,5\% no Brasil e 13,6\% em Minas Gerais. Já a proporção de pentecostais em Ribeirão das Neves é quase o dobro da do estado (17,3\% e 9,0\%, respectivamente).

Analisando somente a população entre 15 e 24 anos, os números da Tabela 3 indicam que a proporção de católicos é praticamente idêntica à população total. No Brasil e em Minas Gerais, a proporção de evangélicos (protestantes históricos) também é bastante semelhante, mas não em Ribeirão das Neves. Não surpreende o fato do grupo que se

\footnotetext{
${ }^{2}$ Cf. PLANO METROPOLITANO, 2011.
} 
declara sem religião ser relativamente maior entre os jovens, se comparados à população total, já que nessa fase há uma tendência à contestação e rejeição de valores considerados tradicionais e antiquados, entre eles a religião. Há, ainda, uma menor proporção de pentecostais entre os jovens vis-à-vis a população total. Uma possível explicação pode estar na importância da conversão para os pentecostais, processo este que pode ocorrer após os 25 anos de idade. Ribeirão das Neves não é, portanto, uma cidade típica de Minas Gerais ou do Brasil no tocante à filiação religiosa de seus habitantes. Além disso, sabemos que ela é menos católica e mais evangélica do que a média nacional e estadual.

Tabela 3

Distribuição da população (total, 15-19 e 20-24 anos) segundo religião

Brasil, Minas Gerais e Ribeirão das Neves, 2000

\begin{tabular}{l|ccc|ccc|ccc}
\hline \multicolumn{1}{c|}{ Filiação Religiosa } & \multicolumn{3}{|c|}{ Brasil } & \multicolumn{3}{c|}{ Minas Gerais } & \multicolumn{3}{c}{ Ribeirão das Neves } \\
& total & $15-19$ & $20-24$ & total & $15-19$ & $20-24$ & total & $15-19$ & $20-24$ \\
\hline Católica & 73,6 & 74,1 & 73,1 & 78,7 & 78,9 & 78,0 & 62,9 & 61,0 & 64,1 \\
Evangélica & 4,1 & 3,9 & 3,9 & 3,7 & 3,7 & 3,7 & 6,4 & 8,0 & 5,9 \\
Evangélica Pentecostal & 10,4 & 9,2 & 9,4 & 9,0 & 8,2 & 8,3 & 17,3 & 15,8 & 14,1 \\
Outras evangélicas & 1,0 & 0,9 & 0,9 & 0,9 & 0,8 & 0,8 & 1,3 & 1,2 & 0,9 \\
Outras religiões & 3,4 & 2,9 & 3,1 & 3,0 & 2,5 & 2,7 & 2,5 & 1,9 & 1,8 \\
Sem religião & 7,4 & 8,9 & 9,4 & 4,6 & 5,8 & 6,5 & 9,3 & 11,9 & 13,1 \\
Sem declaração & 0,2 & 0,2 & 0,2 & 0,1 & 0,1 & 0,1 & 0,3 & 0,1 & 0,1 \\
\hline \hline
\end{tabular}

Fonte: Censo Demográfico 2000, elaboração própria

Com base na soma daqueles que declaram alguma filiação religiosa, o panorama religioso é tal que $92,4 \%$ da população brasileira, $95,3 \%$ da população mineira e $90,4 \%$ da população nevense tem religião. Será que conhecer este número é suficiente para compreender estes três panoramas religiosos? Será que a inclusão de medidas de religiosidade traria informações adicionais relevantes?

\section{b. 0 retrato mais detalhado}

Ainda no que tange à filiação religiosa, os dados da Pesquisa Jovem revelam que os estudantes entrevistados em 2009 são ainda menos católicos que a população do município em 2000 - 43,4\%, comparados a 62,9\% da população total - e a proporção de evangélicos $(43,7 \%)$ é praticamente igual à de católicos. A proporção dos que se declaram sem religião 
também é elevada $(10,3 \%)$ e, conforme apontado pela literatura, varia muito entre homens e mulheres, com uma proporção consideravelmente maior de homens declarados sem religião (Tabela 4).

Tabela 4

Distribuição dos estudantes segundo sexo e filiação religiosa 1a coorte de Ribeirão das Neves, 2009

\begin{tabular}{lrrr}
\hline \hline Filiação religiosa & Mulheres & Homens & Total \\
\hline Católica & 43,9 & 42,7 & 43,4 \\
Protestantes históricos & 12,4 & 11,6 & 12,0 \\
Protestantes Pentecostais & 25,9 & 23,2 & 24,8 \\
Protestantes neopentecostais & 7,3 & 6,3 & 6,9 \\
Outras religiões & 2,7 & 2,3 & 2,6 \\
Sem religião & 7,8 & 13,9 & 10,3 \\
\hline $\mathrm{N}$ & 437 & 302 & 739 \\
\hline \hline
\end{tabular}

Fonte: Pesquisa Jovem, Ribeirão das Neves, 2009

A primeira medida de religiosidade analisada aqui é a frequência a cerimônias religiosas. Os dados indicam que metade dos estudantes é praticante, ou seja, frequenta cerimônias de sua religião pelo menos uma vez por semana. Analisados separadamente, homens e mulheres têm comportamentos distintos, uma vez que 54,4\% das mulheres são praticantes, comparadas a 41,3\% dos homens. Já a maioria dos homens $(58,7 \%)$ são não praticantes, definidos como aqueles que frequentam as cerimônias menos de uma vez por semana, incluindo aqueles que frequentam apenas os chamados ritos religiosos, comparados a $45,6 \%$ das mulheres.

A participação religiosa, que combina filiação religiosa e frequência às cerimônias, é o próximo passo para a definição de um panorama religioso mais detalhado, conforme a Tabela 5. É importante destacar que, entre os estudantes entrevistados, a maioria dos que se declararam católicos é, na verdade, não praticante, ao contrário dos evangélicos, entre os quais a maioria é praticante.

Horizonte, Belo Horizonte, v. 9, n. 23, p. 715-728, out./dez. 2011 - ISSN: 2175-5841 
Tabela 5

Distribuição dos estudantes segundo a participação religiosa

1a coorte de Ribeirão das Neves, 2009

\begin{tabular}{lccc}
\hline \hline Participação religiosa & Mulheres & Homens & Total \\
\hline Católicos praticantes & 20,1 & 12,9 & 17,2 \\
Católicos não praticantes & 23,8 & 29,8 & 26,3 \\
Protestantes históricos praticantes & 8,0 & 7,0 & 7,6 \\
Protestantes históricos não praticantes & 4,3 & 4,6 & 4,5 \\
Protestantes pentecostais praticantes & 18,3 & 15,2 & 17,1 \\
Protestantes pentecostais não praticantes & 7,6 & 7,9 & 7,7 \\
Protestantes neopentecostais praticantes & 5,7 & 4,6 & 5,3 \\
Protestantes neopentecostais não praticantes & 1,6 & 1,7 & 1,6 \\
Outras religiões & 2,7 & 2,3 & 2,6 \\
Sem religião & 7,8 & 13,9 & 10,3 \\
\hline $\mathrm{N}$ & 437 & 302 & 739 \\
\hline \hline
\end{tabular}

Fonte: Pesquisa Jovem, Ribeirão das Neves, 2009

Apesar da combinação entre filiação religiosa e frequência às cerimônias já ser um avanço importante com relação às possibilidades oferecidas pelos censos demográficos, ela pode não ser suficiente para captar a religiosidade de um indivíduo, uma vez que há manifestações de fé que independem da ida a uma cerimônia religiosa. $\mathrm{Na}$ verdade, nada impede que um indivíduo sem frequência a cerimônias religiosas ou até mesmo sem filiação religiosa tenha religiosidade e a expresse, por exemplo, através de rezas e orações feitas em sua residência.

De fato, os dados da Tabela 6 confirmam que a religiosidade não passa necessariamente por ter uma filiação religiosa ou frequentar as cerimônias da religião. Entre os estudantes que se declararam sem religião, $44,1 \%$ das mulheres e $21,4 \%$ dos homens rezam/oram/fazem preces todos os dias. No caso das mulheres, somente 1/3 reza/ora raramente ou nunca. Esses números sugerem que o grupo declarado sem religião, aqui ou em qualquer outra pesquisa, merece estudos mais aprofundados, uma vez que é extremamente heterogêneo quanto à sua religiosidade. 
Tabela 6

Distribuição dos estudantes segundo participação religiosa e frequência com que rezam/oram/fazem preces fora das cerimônias religiosas

la coorte de Ribeirão das Neves, 2009

\begin{tabular}{|c|c|c|c|c|c|c|c|c|}
\hline \multirow[b]{2}{*}{ Participação religiosa } & \multicolumn{4}{|c|}{ Mulheres rezam/oram/fazem preces } & \multicolumn{4}{|c|}{ Homens rezam/oram/fazem preces } \\
\hline & todo dia & $\begin{array}{c}\text { pelo menos } \\
1 \text { vez por mês }\end{array}$ & $\begin{array}{c}\text { raramente/ } \\
\text { nunca }\end{array}$ & $\mathrm{N}$ & todo dia & $\begin{array}{c}\text { pelo menos } \\
1 \text { vez por mês }\end{array}$ & $\begin{array}{c}\text { raramente/ } \\
\text { nunca }\end{array}$ & $\mathrm{N}$ \\
\hline Católicos praticantes & 75,0 & 18,2 & 6,8 & 88 & 66,7 & 25,6 & 7,7 & 39 \\
\hline Católicos não praticantes & 55,8 & 25,0 & 19,2 & 104 & 42,7 & 30,3 & 27,0 & 89 \\
\hline Protestantes históricos praticantes & 65,7 & 22,9 & 11,4 & 35 & 61,9 & 19,0 & 19,0 & 21 \\
\hline Protestantes históricos não praticantes & 68,4 & 26,3 & 5,3 & 19 & 35,7 & 57,1 & 7,1 & 14 \\
\hline Protestantes pentecostais praticantes & 78,2 & 20,5 & 1,3 & 78 & 67,4 & 26,1 & 6,5 & 46 \\
\hline Protestantes pentecostais não praticantes & 66,7 & 24,2 & 9,1 & 33 & 50,0 & 25,0 & 25,0 & 24 \\
\hline Protestantes neopentecostais praticantes & 60,0 & 36,0 & 4,0 & 25 & 57,1 & 21,4 & 21,4 & 14 \\
\hline Protestantes neopentecostais não praticantes & 57,1 & 28,6 & 14,3 & 7 & 60,0 & 40,0 & 0,0 & 5 \\
\hline Outras religiões & 75,0 & 16,7 & 8,3 & 12 & 85,7 & 14,3 & 0,0 & 7 \\
\hline Nenhuma religião & 44,1 & 23,5 & 32,4 & 34 & 21,4 & 16,7 & 61,9 & 42 \\
\hline
\end{tabular}

Fonte: Pesquisa Jovem, Ribeirão das Neves, 2009

Outra comparação interessante é a de mulheres com homens. A proporção de mulheres que reza/ora todos os dias é sempre mais elevada que a de homens, exceto entre os neopentecostais não praticantes, cujo número de casos é muito pequeno para que se possa dizer algo a respeito deles. O reverso ocorre com rezas e preces feitas raramente ou nunca, categoria com sobrerrepresentação masculina.

Finalmente, cabe ressaltar que proporção de não praticantes que reza/ora todos os dias é relativamente alta, o que pode estar sugerindo alguma dificuldade em frequentar as cerimônias, seja por falta de tempo ou qualquer outra razão. Assim, não frequentar as cerimônias regularmente não é sinônimo de baixa religiosidade. Portanto, levar em consideração a dimensão da religiosidade no âmbito doméstico, além da filiação religiosa e da frequência às cerimônias, pode significar um passo além no entendimento do panorama religioso. 


\section{Comentários finais}

O objetivo deste artigo foi, através do exemplo do município de Ribeirão das Neves-MG, mostrar que a filiação religiosa não é suficiente para entender a complexidade do panorama religioso brasileiro. Foram utilizados dados do Censo Demográfico de 2000 e da Pesquisa Jovem de 2009.

Os resultados indicam que Ribeirão das Neves é distinta de Minas Gerais e do Brasil no que tange à filiação religiosa - o município é menos católico, mais protestante e mais pentecostal que o estado e o país. A frequência religiosa indica que a maioria dos católicos e católicas da amostra são não praticantes e somente $2 / 5$ dos homens frequenta as cerimônias pelo menos uma vez por semana. Medida de religiosidade no âmbito doméstico revela que, na verdade, 2/5 das mulheres e 1/5 dos homens que se declaram sem religião rezam/oram/fazem preces todos os dias. Portanto, a filiação religiosa é insuficiente para compreender o panorama religioso e é preciso ir além.

Em nossa opinião, não caberia aos censos demográficos o papel de investigar a religiosidade da população brasileira, pois o questionário da amostra já é bastante extenso e o custo de incluir novas perguntas seria muito elevado. Pesquisas amostrais como a Pesquisa Nacional por Amostra de Domicílios - PNAD poderiam suprir esta lacuna se incluíssem o quesito do censo, somado a uma ou mais medidas de religiosidade. Fica a sugestão para o IBGE.

\section{REFERÊNCIAS}

COUTINHO, R.Z.; MACHADO, C.J.; MIRANDA-RIBEIRO, P. Religião, religiosidade e iniciação sexual na adolescência: meio século de pesquisas. Belo Horizonte: Cedeplar. 2011. (Textos para Discussão Cedeplar).

ELLISON, C.G., HUMMER, R.A.. Introduction. In: ELLISON, C.G.; HUMMER, R.A. (eds.). Religion, Families and Health: Population-Based Research in the United States. New Brunswick: Rutgers, 2010. p.1-15.

ELLISON, C.G.; HUMMER, R.A.; CORMIER, S.; ROGERS, R.G. Religious Involvement and Mortality Risk among African American Adults. Research on Aging, Thousand Oaks, v. 22, n. 6, p. 630-667, nov. 2000. 
HUMMER, R.A. et al. Religious Involvement and Adult Mortality in the United States: Review and Perspective. Southern Medical Journal, Birmingham v. 97, n. 12, p. 12231230, 2004.

INSTITUTO BRASILEIRO DE GEOGRAFIA E ESTATÍSTICA. Uma análise da população com base nos resultados dos Censos Demográficos 1940 e 2000. Rio de Janeiro: IBGE, 2007.

INSTITUTO BRASILEIRO DE GEOGRAFIA E ESTATÍSTICA. Tendências

Demográficas: Uma análise dos resultados da amostra do Censo Demográfico 2000. Rio de Janeiro: IBGE, 2004.

LEHRER, E.L. Religion as a Determinant of Economic and Demographic Behavior in the United States. Population and Development Review, New York, v. 30, n. 4, p. 707-726, nov. 2004. Disponível em < http://ftp.iza.org/dp1390.pdf>. Acesso em: 02 mar. 2010.

LEHRER, E.L. Religion as a Determinant of Marital Stability. Demography, Silver Spring, v. 30 n. 3, p. 385-404, aug. 1993.

MIRANDA-RIBEIRO, P.; LONGO, L.A.F.B.; MARTELETO, L.J. What's God Got to Do with It? Religion, Religiosity, and Union Formation among Women in Brazil. In:

Population Association Of America Annual Meeting, Dallas, April 15-17 2010, Extended abstract. Disponível em <http://bit.ly/tG8lk4>. Acesso em: 18 ago. 2011.

OGLAND, C. P.; BARTKOWSKI, J. P.; SUNIL, T. S.; XU, X. Religious Influences on Teenage Childbearing among Brazilian Female Adolescents: A Research Note. Journal for the Scientific Study of Religion. Provo, v. 49, n. 4, p. 754-760, 2010.

PEARCE, L.D. Religion and the Timing of First Births in the United States. In: ELLISON, C.G.; HUMMER, R.A. (eds). Religion, Families and Health: Population-Based Research in the United States. New Brunswick: Rutgers University Press, 2010. p.19-39.

PLANO METROPOLITANO. Região Metropolitana de Belo Horizonte. Disponível em: <http://www.rmbh.org.br/index.php?option=com_content \&view=article\&id=97\&Itemid=7 3>. Acesso em: 01 set. 2011.

ROGERS, R.G.; KRUEGER, P.M.; HUMMER, R.A. Religious Attendance and CauseSpecific Mortality in the United States. In: ELLISON, C.G., HUMMER, R.A. (Ed.). Religion, Families and Health: Population-Based Research in the United States. New Brunswick: Rutgers University Press, 2010. p.292-320.

SHERKAT, D.E. The Religious Demography of the United States: Dynamics of Affiliation, Participation, and Belief. In: ELLISON, C.G.; HUMMER, R.A. (Ed.). Religion, Families and Health: Population-Based Research in the United States. New Brunswick: Rutgers University Press, 2010. p. 403-430. 
SMITH, C.; SIKKINK, D.; BAILEY, J. Devotion in Dixie and beyond: A test of the" Shibley thesis" on the effects of regional origin and migration on individual religiosity. Journal for the Scientific Study of Religion. Provo, v. 37, n. 3, p. 494-506, set. 1998.

SOUSA, E.A.. Ribeirão das Neves: a formação do espaço periférico. In: ANDRADE, Luciana Teixeira de.; MENDONÇA, Jupira Gomes de.; FARIA, Carlos Aurélio Pimenta de, Metrópole: território, sociedade e política: o caso da Região Metropolitana de Belo Horizonte. Belo Horizonte: PUC Minas, 2008. p. 265-293.

THORNTON, A.; CAMBURN, D. Religious Participation and Adolescent Sexual Behavior and Attitudes. Journal of Marriage and Family. Minneapolis, v. 51, n. 3, p. 641-653, aug. 1989.

VERONA, A.P.A.; DIAS JÚNIOR, C.S.. A relação entre o pentecostalismo e o comportamento reprodutivo de adolescentes no Brasil. XV Congresso Brasileiro de Sociologia, 2011, Curitiba. Anais XV Congresso Brasileiro de Sociologia. Curitiba, 2011a.

VERONA, AP.A.; DIAS JÚNIOR, C.S. Religião e fecundidade entre adolescentes no Brasil. Revista Panamericana de Salud Pública/Pan American Journal of Public Health, Washington, 2011b. (No prelo).

VERONA, A.P.A.; DIAS JÚNIOR, C.S. Trends and associations between religion, religiosity and sexual initiation in Brazil. XVII Encontro Nacional De Estudos Populacionais, 2010, Caxambu. Anais XVII Encontro Nacional de Estudos Populacionais. Caxambu, 2010. p. 84-85.

VERONA, A.P.A.; HUMMER, R.A.; DIAS JÚNIOR, C.S; LIMA, L.C.. Infant Mortality and Mother s Religious Involvement in Brazil. Revista Brasileira de Estudos de População. São Paulo, v. 27, n. 1, jan./jun. 2010, p. 59-74.

VERONA, A.P.A.; REGNERUS, M. Premarital Sexual Initiation and Fertility among Pentecostal Adolescents in Brazil. Population Association Of America Annual Meeting, 2011, Washington DC. Disponível em <http://bit.ly/sxpKAb>. Acesso em: 18 ago 2011.

VERONA, A.P.A.; REGNERUS, M. Religion and Sexual Initiation in Brazil. Population Association Of America Annual Meeting, 2009, Detroit. Disponível em <http://bit.ly/sE67iN>. Acesso em: 18 ago 2011. 